\title{
Salmeterol in exercise-induced bronchoconstriction in asthmatic children: comparison of two doses
}

\author{
F.M. de Benedictis, G. Tuteri, P. Pazzelli, A. Niccoli, D. Mezzetti, R. Vaccaro
}

\begin{abstract}
Salmeterol in exercise-induced bronchoconstriction in asthmatic children: comparison of two doses. F.M. de Benedictis, G. Tuteri, P. Pazzelli, A. Niccoli, D. Mezzetti, R. Vaccaro. CERS Journals Ltd 1996.

ABSTRACT: Since the optimal dose of salmeterol in asthmatic children has not yet been clearly defined, we compared the efficacy and duration of the protective effect of two doses of salmeterol ( 25 and $50 \mu \mathrm{g}$ ) against exercise-induced bronchoconstriction.

Twelve children (aged 7-14 yrs) with asthma were studied in a double-blind, cross-over, placebo-controlled design. On three separate days, exercise tests were performed $1 \mathrm{~h}$ and $12 \mathrm{~h}$ after administration of the drug. Pulmonary function measurements were performed before drug inhalation, before every exercise test and 1 , $5,10,15$ and 30 min after the end of exercise. The response was expressed as maximal decrease in forced expiratory volume in one second (FEV1).

Both doses of salmeterol provided significant bronchodilation for up to $12 \mathrm{~h}$, with no difference between them. Maximal exercise-induced decrease in FEV1 ( $\%$ fall) $1 \mathrm{~h}$ after pretreatment was (mean \pm SD) $35 \pm 16,10 \pm 10$ and $4 \pm 3 \%$ for placebo, 25 and $50 \mu$ g salmeterol, respectively. At $12 \mathrm{~h}$ after pretreatment these values were 31 \pm 14 , $19 \pm 12$ and $15 \pm 13 \%$, respectively. Individual protection against exercise-induced bronchoconstriction at 1 and $12 \mathrm{~h}$ did not vary between the dosages $(\mathrm{p}<0.05)$, even though the protection obtained by $25 \mu \mathrm{g}$ at $12 \mathrm{~h}$ was no longer significant versus placebo.

We conclude that $25 \mu \mathrm{g}$ of inhaled salmeterol provides equally effective long-lasting bronchodilation and acute protection against exercise-induced bronchoconstriction as $\mathbf{5 0} \boldsymbol{\mu g}$, and may be a suitable dose for most asthmatic children.

Eur Respir J., 1996, 9, 2099-2103.
\end{abstract}

Pediatric Dept, University of Perugia, Italy.

Correspondence: F.M de Benedictis

Clinica Pediatrica

Policlinico Monteluce

06100 Perugia

Italy

Keywords: Children

exercise-induced asthma

salmeterol

Received: September 71995

Accepted after revision June 201996
Exercise frequently stimulates bronchoconstriction in children, which is commonly referred to as "exercise-induced asthma" (EIA). These children are often discouraged from physical activities for fear of breathlessness. The currently available beta $_{2}$-adrenoceptor agonists by the inhaled route will prevent EIA in about $90 \%$ of patients when given prior to activity [1]. However, the duration of their protective effect is usually less than $2 \mathrm{~h}[2$, $3]$, probably because of the hydrophilic nature of these agents and their rapid clearance from the airways [4].

Salmeterol xinafoate is a new, selective, long-acting beta $_{2}$-adrenoceptor agonist. It has a polar phenylethanolamine head which binds reversibly to the beta 2 -receptor, and a long nonpolar side-chain which binds to the cell membrane adjacent to the receptor and to which is attributed the long duration of the effect [5].

The optimal dose of salmeterol in asthmatic children has not yet been clearly defined. The commonly recommended adult dose has been used in children [6, 7]. However, both single dose studies $[8,9]$ and long-term treatment [10] have shown that 25 and $50 \mu \mathrm{g}$ of salmeterol have comparable bronchodilator effects and are equally useful in controlling symptoms in children.

As very few data are available on the efficacy and duration of the protective effect of salmeterol in EIA in children, we compared two doses $(25$ and $50 \mu \mathrm{g})$ in order to provide guidance for an optimal dosage.

Materials and methods

\section{Subjects}

Twelve subjects (10 males and 2 females) aged 7-14 yrs (mean \pm SD $11 \pm 2$ yrs) were recruited. All patients attended the Paediatric Asthma Clinic at Perugia General Hospital and had asthma as defined by the American Thoracic Society (ATS) [11]. They were being treated with different antiasthma regimens, such as short-acting $\beta$-agonists, cromolyn, nedocromil and inhaled steroids. These drugs were withheld for $12 \mathrm{~h}$ before each exercise test. None of the subjects had a history of respiratory infection in the 4 weeks before the trial. Informed consent was obtained from patients and their parents, and the protocol was approved by the Hospital Ethics Committee.

\section{Study design}

Before study entry, a screening exercise test was performed. The exercise test consisted of steady-state running 
for 6 min on an inclined treadmill to produce a heart rate of at least $85 \%$ of the maximum predicted for age. Nasal clips were used when breathing ambient air during the test. The exercise workload for each subject was determined on the basis of an incremental Stage 1 exercise test, and was kept constant throughout the study [12]. Only subjects who demonstrated a drop of at least $15 \%$ from baseline in forced expiratory volume in one second (FEV1) after the exercise screening test entered the blinded phase of the study. In random, cross-over, blinded order, on three separate days, each patient was tested with different treatments inhaled by metered-dose inhaler (MDI): salmeterol (two puffs $=50 \mu \mathrm{g}$ ); salmeterol (one puff $=25 \mu \mathrm{g}$ ) plus placebo (one puff); or placebo (two puffs). Patients were randomized so that an equal number of patients received each drug as the first, second and third drug, respectively, employing a Greek-Latin square design. The drugs were administered by a trained physician, and all patients were skilled in the use of MDIs. The "closed mouth" technique was used. On each of the three study days, patients attended the laboratory between 08:00 and 09:00 $\mathrm{h}$ and performed the exercise tests, respectively, 1 and $12 \mathrm{~h}$ after inhalation of each drug. Room temperature and relative humidity were monitored in a climate room. Differences of $1^{\circ} \mathrm{C}$ in temperature and $0.1 \mathrm{kPa}$ in vapour pressure of water on the test days of each patient were considered acceptable. Room temperatures ranged $21-23^{\circ} \mathrm{C}$ and relative humidity ranged $41-58 \%$.

\section{Pulmonary function measurements}

Pulmonary function was measured with a turbine spirometer (Pocket Spirometer I; Micro Medical Ltd, Rochester, Kent, UK) according to accepted standards [13]. Predicted normal values for spirometry were obtained from the study of KNUDSON et al. [14]. All children were familiar with the spirometer. Measurements were performed before drug inhalation (baseline value), before every exercise test (pre-exercise value), and 1, 5, 10, 15 and $30 \mathrm{~min}$ after the end of exercise. Heart rate was measured before the administration of the trial medication, before exercise, and at specific times until $30 \mathrm{~min}$ after the end of exercise. The exercise test was performed only if the baseline FEV1 was higher than $70 \%$ of the mean predicted for the child's height, and if the baseline FEV1 varied $<10 \%$ from the values on previous test days.

\section{Exercise challenge parameters}

The following parameters were calculated from the results of the pulmonary function tests. The maximum $\%$ drop in FEV1 was calculated as follows:

Pre-exercise FEV1 - lowest postexercise FEV1 Pre-exercise FEV1

"Complete protection" was considered to have been obtained if the percentage drop in FEV1 was within the normal range $(<10 \%)$. "Clinical protection" was considered to have been obtained if the percentage fall in FEV1 after receiving the active drug was half or less of the percentage fall after the screening [15].
In addition, the time (min) for FEV1 to recover to within $10 \%$ of the pre-exercise value was determined.

\section{Statistical analysis}

The pre-treatment FEV1 values on the three study days were compared using one-way analysis of variance (ANOVA). Two-way ANOVA was used to analyse the following indices, with drug and time after treatment (at 1 and $12 \mathrm{~h}$ ) as factors: 1) change from baseline in values of FEV1 before exercise; and 2) maximum falls in FEV1 after exercise. When appropriate, multiple comparisons were performed by means of the Tukey studentized test. McNemars change test was used to compare the number of patients who had complete or clinical protection with different drugs. Where the expected frequency for McNemars test was too small $($ e.g. $<0.5)$ the binomial test was used.

The time to return to $10 \%$ of the pre-exercise FEV1 was analyzed nonparametrically using Wilcoxon's rank sum test. Because the FEV1 did not return to within $10 \%$ of the pre-exercise value at $30 \mathrm{~min}$ after the exercise test in some subjects, 30 min was used as a minimal estimate of the time for recovery.

Factors influencing the change in FEV1 after treatment and the maximum fall in FEV1 after exercise were analysed by multiple regression analysis of pretreatment FEV1, treatment, treatment order, and time-point after treat-ment. Analysis of covariance (ANCOVA) was used to assess the impact of bronchodilation on the bronchoprovocative airway responses. The analysis was performed with Statistical Analysis System (SAS) software. Differences were considered significant at a p-value less than $0.05[16]$.

\section{Results}

Intervals between study days ranged 2-10 days. Pretreatment (baseline) values for FEV1 on the three study days ranged $88-119 \%$ (mean \pm SD $94 \pm 6 \%$ ) of predicted values. There was no difference between the pre-treatment FEV1 values on the three study days.

Mean $( \pm \mathrm{SD})$ pretreatment and pre-exercise FEV1 values, and FEV1 changes from baseline in response to treatment are shown in table 1. After placebo inhalation, FEV1 at both pre-exercise times did not change significantly from the baseline. After inhalation of $25 \mu \mathrm{g}$ salmeterol (SLM 25) and $50 \mu \mathrm{g}$ salmeterol (SLM 50), FEV1 change

Table 1. - Pretreatment and pre-exercise FEV1 values and percentage change from baseline on the three study days

\begin{tabular}{|c|c|c|c|}
\hline & Placebo & SLM25 & SLM50 \\
\hline Pret & $2.02 \pm 0.3$ & $2.01 \pm 0.4$ & $2.02 \pm 0.3$ \\
\hline Pre-exercise at $1 \mathrm{~h} \mathrm{FEV} 1 \mathrm{~L}$ & $2.11 \pm 0.4$ & $2.24 \pm 0.4$ & $2.23 \pm 0.3$ \\
\hline$\triangle \mathrm{FEV}_{1} \%$ & $3.9 \pm 4.3$ & $11.7 \pm 8.6$ & $10.8 \pm 5.0$ \\
\hline Pre-exercise at $12 \mathrm{~h}$ FEV 1 L & $2.00 \pm 0.4$ & $2.16 \pm 0.3$ & $2.21 \pm 0.4$ \\
\hline$\triangle \mathrm{FEV}_{1} \%$ & $-1.2 \pm 5.1$ & $8.0 \pm 7.3$ & $9.5 \pm 5.3$ \\
\hline
\end{tabular}

Values are presented as mean \pm SD. SLM25: salmeterol $25 \mu \mathrm{g}$; SLM50: salmeterol $50 \mu \mathrm{g}$; FEV1: forced expiratory volume in one second; $\triangle \mathrm{FEV} 1$ : change in FEV1. 
Table 2. - Maximum percentage decrease in $\mathrm{FEV}_{1}$ at screening and after the first and the second exercise test with each treatment

\begin{tabular}{cccccccc}
\hline & \multicolumn{8}{c}{ Maximum decrease in FEV1 } & \multicolumn{3}{c}{} \\
\cline { 2 - 8 } Pt. & Screening & \multicolumn{2}{c}{ Placebo } & \multicolumn{2}{c}{ SLM25 } & \multicolumn{2}{c}{ SLM50 } \\
No. & & $1 \mathrm{~h}$ & $12 \mathrm{~h}$ & $1 \mathrm{~h}$ & $12 \mathrm{~h}$ & $1 \mathrm{~h}$ & $12 \mathrm{~h}$ \\
\hline 1 & 28 & 35 & 26 & 24 & 25 & 6 & 15 \\
2 & 60 & 48 & 46 & 27 & 30 & 10 & 39 \\
3 & 28 & 30 & 8 & 0 & 6 & 0 & 2 \\
4 & 20 & 35 & 29 & 1 & 3 & 0 & 4 \\
5 & 28 & 19 & 23 & 2 & 8 & 5 & 7 \\
6 & 57 & 61 & 50 & 1 & 12 & 3 & 14 \\
7 & 31 & 19 & 25 & 4 & 6 & 4 & 5 \\
8 & 41 & 60 & 50 & 24 & 34 & 6 & 41 \\
9 & 27 & 27 & 23 & 3 & 33 & 3 & 21 \\
10 & 69 & 54 & 48 & 6 & 22 & 3 & 11 \\
11 & 23 & 20 & 18 & 18 & 27 & 8 & 10 \\
12 & 23 & 28 & 25 & 7 & 26 & 0 & 10 \\
\hline Mean & 36 & 35 & 31 & 10 & 19 & 4 & 15 \\
\pm sD & 16 & 16 & 14 & 10 & 12 & 3 & 13 \\
\hline
\end{tabular}

Pt: patients. For definitions see legend to table 1.

was significantly greater than after placebo (PL), both at $1 \mathrm{~h}$ (SLM 25: $\mathrm{p}<0.02$; SLM 50: $\mathrm{p}<0.05)$ and at $12 \mathrm{~h}$ (SLM 25: $\mathrm{p}<0.05$; SLM 50: $\mathrm{p}<0.001$ ). No significant interdose difference emerged in the FEV1 changes at either time. Multiple regression analysis showed that treatment $(p<0.001)$ and time after treatment $(p<0.02)$ were significant factors for change in FEV1 after treatment.

Table 2 shows the maximum percentage decrease in FEV1 after the first and the second exercise test on each study day. Comparing the maximum percentage decreases in FEV1 showed that SLM 25 and SLM 50 were both significantly better than placebo at $1 \mathrm{~h}$ (SLM 25: $\mathrm{p}<0.001$; SLM 50: p<0.001), but only SLM 50 was more effective than placebo at $12 \mathrm{~h}$ (SLM 50: p<0.05; SLM 25: NS). There was no statistical difference in the mean of the percentage drops in FEV1 between SLM 25 and SLM 50 at either time (fig. 1). Multiple regression analysis

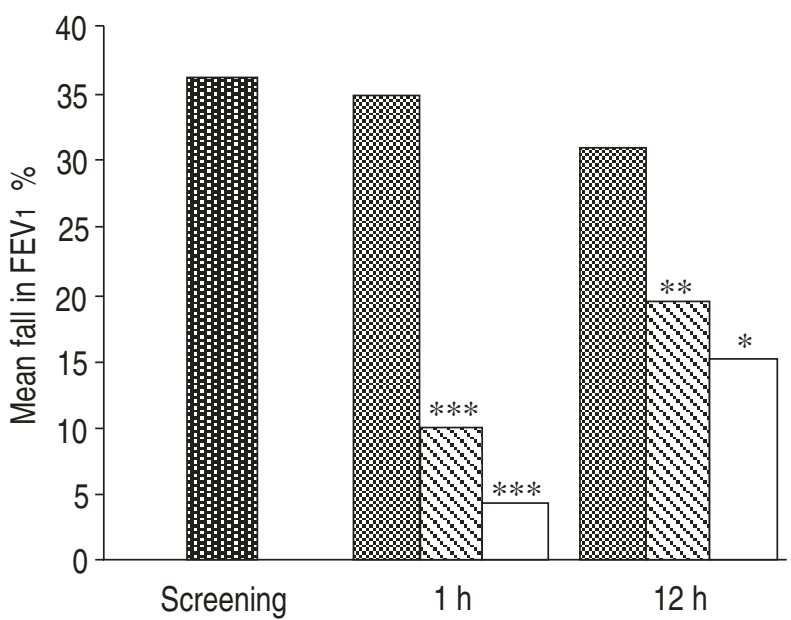

Fig. 1. - Mean percentage decrease in forced expiratory volume in one second $\left(\mathrm{FEV}_{1}\right)$ at screening and after the first and second exercise test with each treatment. $\%$ : placebo; $\mathbf{0}$ : salmeterol $25 \mu \mathrm{g} ; \square$ : salmeterol $50 \mu \mathrm{g} . *$, **, ***: $\mathrm{p}<0.05,<0.01,<0.001 \mathrm{vs}$ placebo.
Table 3. - Individual protection against exercise-induced bronchoconstriction in asthmatic children $(n=12)$ and mean time for recovery of $F E V_{1}$ to $10 \%$ of pre-exercise values

\begin{tabular}{|c|c|c|c|c|c|c|}
\hline & \multicolumn{3}{|c|}{$1 \mathrm{~h}$} & \multicolumn{3}{|c|}{$12 \mathrm{~h}$} \\
\hline & PL & $\begin{array}{l}\text { SLM } \\
25\end{array}$ & $\begin{array}{l}\text { SLM } \\
50\end{array}$ & PL & $\begin{array}{l}\text { SLM } \\
25\end{array}$ & $\begin{array}{c}\text { SLM } \\
50\end{array}$ \\
\hline $\begin{array}{l}\text { Complete } \\
\text { protection } \mathrm{n}\end{array}$ & 0 & $8 * *$ & $12 * * *$ & 1 & 4 & $6^{*}$ \\
\hline $\begin{array}{l}\text { Clinical }(>50 \%) \\
\text { protection } \mathrm{n}\end{array}$ & 0 & $9 * *$ & $12 * *$ & 1 & $7 *$ & $8^{*}$ \\
\hline $\begin{array}{l}\text { Mean recovery } \\
\text { time min }\end{array}$ & 23 & $5 * *$ & $0 * *$ & 18 & 13 & $7 * *$ \\
\hline
\end{tabular}

$*, * *, * * *: \mathrm{p}<0.05,<0.01,<0.001$ vs placebo (PL). For definitions see legends to tables 1 and 2 .

showed that significant factors for fall in FEV1 after exercise were treatment $(\mathrm{p}<0.001)$ and time after treatment $(p<0.05)$. ANCOVA revealed a weak correlation $(p<0.1)$ between the change in FEV1 after treatment and the fall in FEV1 after exercise at both times, that is protection from exercise-induced bronchoconstriction was not dependent on bronchodilation.

The mean time (min) for recovery of FEV1 to $10 \%$ of pre-exercise values was significantly shorter for SLM 25 and SLM 50 at $1 \mathrm{~h}$ and for SLM 50 at $12 \mathrm{~h}$, with respect to placebo. There was no significant difference between SLM 25 and SLM 50 at either exercise challenge (table 3 ).

\section{Individual protection}

After the first exercise challenge, complete protection was provided in $67 \%$ of patients with SLM 25, in all patients with SLM 50, and none with placebo. The number of protected patients decreased after the second exercise test: only 33\%, 50\% and $8 \%$ of the subjects were completely protected by SLM 25, SLM 50, and placebo, respectively (table 3 ).

Clinical $(>50 \%)$ protection was present in $75 \%, 100 \%$ and none of the patients after the first exercise challenge, and in 58\%, 66\%, $8 \%$ after the second challenge for SLM 25, SLM 50 and placebo, respectively (table 3).

Unwanted side-effects were not observed by the physician or referred by any patients. No significant changes were observed in heart rate with either treatment.

\section{Discussion}

Salmeterol xinafoate is a new, selective, beta $_{2}$-adrenoceptor agonist, which has been shown to produce sustained bronchodilation and prolonged protection against different stimuli both in adults [17-24] and in children $[6,7,25]$. Several studies have evaluated the protection of beta $_{2}$-adrenoceptor agents against different bronchoconstrictive challenges. Whilst a dose-response effect has been demonstrated for chemical stimuli [17, 25-27], contradictory results have been obtained with exercise $[28,29]$. In the present study, 25 and $50 \mu \mathrm{g}$ doses of salmeterol provided the same protection against EIA at 1 h. After $12 \mathrm{~h}$, although no statistical difference emerged between the two dosages in the mean of the percentage 
drops in FEV1, only SLM 50 was more protective than placebo. However, in drug studies on EIA individual protection is as important as the mean drop in pulmonary function parameters. Interestingly, statistical analysis of complete and clinical protection in individual patients showed no difference between the two dosages even after $12 \mathrm{~h}$. It should be noted, however, that with such a small number of patients any statistical test to evaluate individual protection probably has very little power.

The effects of 25 and $50 \mu \mathrm{g}$ salmeterol on suppression of bronchial hyperresponsiveness in children has been compared in only two studies [25, 30]. Simons et al. [25] demonstrated that both doses are better than placebo against methacholine challenge, but salmeterol $50 \mu \mathrm{g}$ provides significantly greater bronchoprotection than $25 \mu \mathrm{g}$ from $30 \mathrm{~min}$ to $12 \mathrm{~h}$. Although the results of the present study are different, they are not necessarily conflicting. Indeed, the degree and the duration of the protective effect of any drug on airway hyperresponsiveness may vary with the stimulus [31]. Furthermore, the results of methacholine and exercise challenges are not strictly comparable, since the airway response to methacholine is measured in dose-dependent fashion, whereas exercise is always performed at the same level [32].

Very recently, CARLSEN et al. [30] evaluated the overnight protection against EIA afforded by 25 and $50 \mu \mathrm{g}$ of dry powder salmeterol in children. No significant differences in pre- and postexercise lung function were found between the two doses $12 \mathrm{~h}$ after inhalation. Despite differences in times of administration (overnight $v s$ diurnal), methods of delivery (inhaled powder vs metered dose inhaler) and cut-off values for protection (15 vs $10 \%$ ), the results of the present study overlap with those of CARLSEN et al. [30], suggesting that children may benefit and obtain adequate clinical protection even from only $25 \mu \mathrm{g}$ of inhaled salmeterol.

Tachyphylaxis to the functional antagonism of salmeterol against EIA is an emerging problem. Recent studies have shown that 2-4 weeks regular treatment with $50 \mu \mathrm{g}$ twice daily reduced the protective effect of the drug against EIA [33] and cold air challenge [34]. The design of the present study excluded the possibility of this phenomenon, in fact no patient had used salmeterol regularly. Furthermore, the order of treatment did not influence the results. However, given the great clinical significance of this aspect, studies are urgently required to determine whether tachyphylaxis also occurs at lower salmeterol dosages.

The same bronchodilating effect for up to $12 \mathrm{~h}$ was provided by inhalation of 25 or $50 \mu \mathrm{g}$ of salmeterol, confirming previous comparative dose-response results $[8$, $9,25]$. The present study also indicates that the protective effect induced by beta $_{2}$-agonists on EIA does not necessarily occur because of concomitant bronchodilation [35]. The fact that no significant correlation was found between the degree of protective effect and the bronchodilation supports the view that other factors in addition to smooth muscle inhibition play a role in salmeterol-induced protection against exercise. Evaporative water loss from the airway mucosa is considered an important mechanism in the pathogenesis of EIA, since it may cause a transient change in osmolarity of the epithelial fluid, which subsequently induces the release of inflammatory mediators [36]. In this respect, salmeterol could act by stimulating $\mathrm{Cl}^{-}$ion secretion, thus enhancing water transport to the airway epithelium [22]. Moreover, as has been suggested for other beta ${ }_{2}$-agonists, salmeterol could also act by preventing the release of mediators from the lung mast cells [22]. Indeed, when compared with placebo, salmeterol significantly reduces the rise in histamine and leukotriene blood concentrations induced by exercise challenge [23].

The protection against EIA of currently available beta ${ }_{2}-$ agonists is usually of shorter duration than their bronchodilating effect $[37,38]$; this does not seem to be the case for long-acting beta ${ }_{2}$-agonists. In fact, VERBERNE $e t$ al. [7] found that a small but significant reduction of airway sensitivity to methacholine was still present $24 \mathrm{~h}$ after administration of $50 \mu \mathrm{g}$ of salmeterol. Furthermore, MALO et al. [39] observed that about $40 \%$ of their patients presented no significant bronchodilation $12 \mathrm{~h}$ after formoterol, but that all were partially or completely protected by hyperventilation-induced bronchoconstriction. The present study was not designed to evaluate the long-term aspects of bronchodilation and protection, which undoubtedly require specific investigation.

As previously reported $[17,25]$, the long duration of action of salmeterol was not associated with significant side-effects, such as tremor or palpitations. Since tachycardia and tremor are known side-effects of beta -ago- $^{-}$ nists, inhaled salmeterol may represent a major advance for treatment of asthma in children who require bronchodilators in addition to anti-inflammatory therapy. Furthermore, since the time when children exercise is often unpredictable, using a long-acting drug may avoid the need to administer a beta ${ }_{2}$-agonist before every strenuous physical activity and removes the stigma of inhaler use at school.

In conclusion, as the present study demonstrates that both 25 and $50 \mu \mathrm{g}$ salmeterol provide long-acting bronchodilation and protect the majority of children against exercise-induced asthma for at least $12 \mathrm{~h}$, we suggest that $25 \mu \mathrm{g}$ salmeterol may be efficacious for most asthmatic children. Nevertheless, we remain convinced that studies to determine whether tachyphylaxis arises from regular therapy at this dosage should be performed in the near future.

Acknowledgements: The authors thank G.A. Boyd for her valuable help.

\section{References}

1. Anderson SD, Seale JP, Ferris L, Schoeffel RE, Lindsay DA. An evaluation of pharmacotherapy for exerciseinduced asthma. J Allergy Clin Immunol 1979; 64: 612-624.

2. Sly RM. Beta-adrenergic drugs in the management of asthma in athletes. J Allergy Clin Immunol 1974; 73: 680-685.

3. Woolley M, Anderson SD, Quigley BM. Duration of protective effect of terbutaline sulfate and cromolyn sodium alone and in combination on exercise-induced asthma. Chest 1990; 97: 39-45.

4. Anderson SD. Exercise-induced asthma: stimulus, mechanisms, and management. In: Barnes PJ, Rodger I, Thomson NC, eds. Asthma: Basic Mechanisms and Clinical Management. London, Academic Press, 1988; 503-522. 
5. Butchers PR, Cousins SA, Vardey CJ. Salmeterol: a potent and long-acting inhibitor of the release of inflammatory and spasmogenic mediators from human lung. $\mathrm{Br} J$ Pharmacol 1987; 92 (Suppl.): 745P.

6. Green CP, Price JF. Prevention of exercise-induced asthma by inhaled salmeterol xinafoate. Arch Dis Child 1992; 67: 1014-1017.

7. Verberne A, Hop WCJ, Bos AB, Kerrebijn K. Effect of a single dose of inhaled salmeterol on baseline airway caliber and methacholine-induced airway obstruction in asthmatic children. J Allergy Clin Immunol 1993; 91: 127-134.

8. Bierman CW, Kemp JP, Sharpe MJ, Georgens J. Salmeterol a beta ${ }_{2}$-agonist induces bronchodilation for $12 \mathrm{~h}$ or greater: a placebo controlled single dose study. J Allergy Clin Immunol 1991; 85: A198.

9. Sandström T, Frederiksen B, Rosenhall L, Sandström B. Salmeterol: a dose-response study with a long acting inhaled beta 2 -agonist. Am Rev Respir Dis 1989; 139: A64.

10. Verberne A, Lenney W, Kerrebijn K. A 3-way crossover study comparing twice daily dosing of salmeterol $25 \mu \mathrm{g}$ and $50 \mu \mathrm{g}$ with placebo in children with mild-tomoderate reversible airways disease. Am Rev Respir Dis 1991; 143: A20.

11. American Thoracic Society. Chronic bronchitis, asthma, and pulmonary emphysema. Am Rev Respir Dis 1962; 85: 762-768.

12. Jones NL. In: Clinical exercise testing. 3rd edn. Philadelphia, W.B. Saunders, 1988; pp. 135-144.

13. Taussig LM, Chernick V, Wood R, Farrell P, Mellins RB. Standardization of lung function testing in children. J Pediatr 1980; 97: 668-676.

14. Knudson RJ, Slatin RC, Lebowitz RD, Burrows B. The maximal expiratory flow volume curve: normal standards, variability, and effects of age. Am Rev Respir Dis 1976; 113: $587-600$

15. Silverman M, Anderson SD. Standardization of exercise tests in asthmatic children. Arch Dis Child 1972; 47: 882887.

16. Altman DG. In: Practical statistics for medical research. London, Chapman and Hall, 1991; p. 211.

17. Derom EY, Pauwels RA, Van der Straeten MEF. The effect of inhaled salmeterol on methacholine responsiveness in subjects with asthma up to $12 \mathrm{~h}$. J Allergy Clin Immunol 1992; 89: 811-815.

18. Campos Gongora H, Wisnieuwski AFZ, Tattersfield AE. A single-dose comparison of inhaled albuterol and two formulations of salmeterol on airway reactivity in asthmatic subjects. Am Rev Respir Dis 1991; 144: 626-629.

19. Malo JL, Ghezzo H, Trudeau $\mathrm{C}$, L'Archevèque J, Cartier A. Salmeterol, a new inhaled beta 2 -adrenergic agonist, has a longer blocking effect than albuterol on hyperventilation-induced bronchoconstriction. J Allergy Clin Immunol 1992; 89: 567-574.

20. Twentyman OP, Finnerty JP, Harris AL, Palmer J, Holgate ST. Protection against allergen-induced asthma by salmeterol. Lancet 1990; 2: 1338-1342.

21. Newnham DM, Ingram CG, Earnshaw J, Palmer JBD, Dhillon DP. Salmeterol provides prolonged protection against exercise-induced bronchoconstriction in a majority of subjects with mild, stable asthma. Respir Med 1993; 87: 439-444.

22. Anderson SD, Rodwell LT, Du Toit J, Young IH. Duration of protection by inhaled salmeterol in exercise-induced asthma. Chest 1991; 100: 1254-1260.
23. Sichletidis L, Daskalopoulou E, Kyriazis G, et al. Comparative efficacy of salbutamol and salmeterol in exercise-induced asthma. J Int Med Res 1993; 21: 81-88.

24. Kemp JP, Dockhorn RJ, Busse WW, Bleecker ER, Van As A. Prolonged effect of inhaled salmeterol against exercise-induced bronchospasm. Am J Respir Crit Care Med 1994; 150: 1612-1615.

25. Simons FE, Reeni Soni N, Watson WT, Becker AB. Bronchodilator and bronchoprotective effects of salmeterol in young patients with asthma. J Allergy Clin Immunol 1992; 90: 840-846.

26. Britton J, Hanley SP, Garrett HV, Hadfield JW, Tattersfield AE. Dose-related effects of salbutamol and ipratropium bromide on airway calibre and reactivity in subjects with asthma. Thorax 1988; 43: 300-305.

27. Higgins BG, Powell RM, Cooper S, Tattersfield AE. Effect of salbutamol and ipratropium bromide on airway calibre and bronchial reactivity in asthma and chronic bronchitis. Eur Respir J 1991; 4: 415-420.

28. O'Byrne PM, Morris M, Roberts R, Hargreave FE. Inhibition of the bronchial response to respiratory heat exchange by increasing doses of terbutaline sulphate. Thorax 1982; 37: 913-917.

29. Magnussen H, Rabe KF. The protective effect of lowdose inhaled fenoterol against methacholine and exercise-induced bronchoconstriction in asthma: a dose-response study. J Allergy Clin Immunol 1992; 90: 846-851.

30. Carlsen K-H, Roksund O, Olsholt K, Nja F, Leegaard J, Bratten G. Overnight protection by inhaled salmeterol on exercise-induced asthma in children. Eur Respir J 1995; 8: 1852-1855.

31. Kerrebijn KF. Beta-agonists. In: Kaliner M, Barnes P, Persson C, eds. Asthma, its Pathology and Treatment. Lung Biology in Health and Disease. New York, Marcel Dekker, 1991; pp. 523-559.

32. de Benedictis FM, Canny GJ, MacLusky IB, Levison H. Comparison of airway reactivity induced by cold air and methacholine challenges in asthmatic children. Pediatr Pulmonol 1995; 19: 326-329.

33. Ramage L, Lipworth BJ, Ingram CG, Cree IA, Dhillon DP. Reduced protection against exercise-induced bronchoconstriction after chronic dosing with salmeterol. Respir Med 1994; 88: 363-368.

34. Gustaffsson PM, Ekstrom T, Forsstrom E, Rimas N. Bronchial hyperresponsiveness (BHR) and protection by salmeterol against bronchial cold-air challenge (CACh) during regular salmeterol treatment in steroid-treated asthmatics. Eur Respir J 1995; 8 (Suppl. 19): 455s.

35. Eggleston PA, Beasley PP. Bronchodilation and inhibition of induced asthma by adrenergic agonists. Clin Pharmacol Ther 1981; 29: 505-510.

36. Spector SL. Update on exercise-induced asthma. Ann Allergy 1993; 71: 571-577.

37. Francis PWJ, Krastins IRB, Levison H. Oral and inhaled salbutamol in the prevention of exercise-induced bronchospasm. Pediatrics 1980; 86: 103-108.

38. Salome CM, Schoeffel RE, Yan K, Woolcock AJ. Effect of aerosol fenoterol on the severity of bronchial hyperreactivity in patients with asthma. Thorax 1983; 38: 854858.

39. Malo JL, Cartier A, Trudeau C, Ghezzo H, Gontovnick L. Formoterol, a new inhaled beta ${ }_{2}$-adrenergic agonist, as a longer blocking effect than albuterol on hyperventilation induced bronchoconstriction. Am Rev Respir Dis 1990; 142: 1147-1152. 